\title{
Effect of Neuro Dynamic Technique and Instrument Assisted Soft Tissue Mobilization on Lower Extremity Muscle Tone, Stiffness, Static Balance in Stroke Patients
}

\author{
Myeong-Jun Kim¹, Tae-Ho Kim² \\ 'Department of Physical Therapy, Daegu Goodmorning hospital, Daegu, Republic of Korea; ${ }^{2}$ Department of Physical Therapy, College of \\ Rehabilitation Science, Daegu University, Daegu, Republic of Korea
}

Purpose: This study was undertaken to compare the efficacy of instrument assisted soft tissue mobilization (IASTM) and a neural dynamic technique (NDYT). As an intervention to treat spastic lower limb muscle tone, stiffness, and static balance in stroke patients.

Methods: Totally, 26 participants were assigned randomly to two groups: the IASTM $(n=13)$ and NDYT $(n=13)$ groups. Both groups were subjected to their respective technique for 15 minutes, 5 times a week, for 6 weeks. Muscle tone, stiffness, and static balance were evaluated before and after training, to compare both group changes.

Results: IASTM group showed significant decrease in the gastrocnemius medial region and semitendinosus muscle tone and stiffness $(p<0.05)$ compare to NDYT group; however, no significant different was observed in static balance between groups ( $p>0.05)$.

Conclusion: The results suggest that IASTM is an effective method for decreasing the muscle tone and stiffness in acute stroke patients.

Keywords: Balance, IASTM, Muscle tone, Neural dynamic technique, Stiffness

\section{INTRODUCTION}

Stroke is a cerebrovascular disease resulting from abrupt blockage or rupture of the blood vessel supplying blood to the brain. ${ }^{1}$ Most stroke patients present with a one-sided paralysis of the body, along with loss of balance due to decreased motor and cognitive functions and damaged sensation, thereby increasing the risk of falls and decreased activity in daily living., ${ }^{2,3}$

Spasticity is one of the symptoms of upper motor neuron syndrome, showing increased muscle tone in proportion and dependent on contraction speed, with the hyperexcitability of stretch reflex. It is a form of dystonia, and the spastic co-contraction of agonist and antagonist is due to occurrence of the lesion on the descending tract of the corticospinal tract. ${ }^{4-6}$ The symptoms appear days or weeks after the occurrence of a stroke. Spasticity is a common syndrome appearing in over $30 \%$ of stroke patients, ${ }^{7}$ causing pain, ankylosis, tendon retraction, and muscle weakening in stroke patients, and affecting the voluntary motion, intervention, and balancing ability of muscles. ${ }^{89}$ Thus, spasticity is responsible for limiting

Received Nov 12, 2020 Revised Dec 6, 2020

Accepted Dec 8, 2020

Corresponding author Tae-Ho Kim

E-mail hohoho90@naver.com the successful rehabilitation, and exerts a harmful effect on the daily life and reduces the quality of life. Hence, spasticity needs to be managed for improving the life of stroke patients. ${ }^{10,11}$

A conservative method to treat spasticity is physical therapy intervention, which comprises using physical modalities, including electrical therapy applied directly as transcutaneous electrical nerve stimulation to the spastic areas, or applying it to the dermatome in the corresponding nerve. ${ }^{12}$ Other interventions include applying local vibration stimulation to the local region for somatosensory stimulation, inducing the release of tightness by applying ice, application of heat intervention before the reduce anxiety of the subject and stretching of the tensed area, and the stretching method to increase soft tissues elasticity like muscle, tendon, and ligament in the areas of spasticity ${ }^{13-15}$ Of these, neural dynamic technique (NDYT) is the technique that reduces tension of the neural tissue with the neural sliding phenomenon, and eases the flow of blood supply through the nerve, to help in recovery of the nerve and soft tissue. This therapeutic technique reduces the dynamic sensitivity of the neural tissue,

Copylight (C)2020 The Korean Society of Physical Therapy

This is an Open Access article distribute under the terms of the Creative Commons Attribution Non-commercial License (https:// creativecommons.org/license/by-nc/4.o.) which permits unrestricted non-commercial use, distribution, and reproduction in any medium, provided the original work is properly cited. 
and enhances the tissue compliance for alleviating the symptoms. ${ }^{16,17}$ The instrument assisted soft tissue mobilization (IASTM) method relaxes the fascia, connective tissue, and tightened tissues for recovering movement of the corresponding muscle; the applied principle involves triggering a partial inflammatory response to the region to resynthesize blood, fiber glia, and collagen, and to reduce tension of the muscular tissue for helping functional movement with increased flexibly and efficiency. ${ }^{18,19}$

In a previous study that used NDYT as an intervention, Villafañe et al. ${ }^{20}$ applied botulinum toxin and NDYT for a patient having moderate spasticity of the upper extremity. They reported significant changes in the modified Ashworth measure, pain score, and joint motion range. Castilho et al. ${ }^{21}$ stated that on an average, muscle activation reduced $17 \%$ when measured for muscle activation of the biceps brachii, after executing the neural dynamic technique in 6 stroke patients.

In precedent studies applying IASTM, Cheatham et al. ${ }^{22}$ reported increased threshold of pressure pain and sensory perception ability of the local region after applying Assisted Soft Tissue Mobilization for the region having delayed onset muscle soreness subsequent to exercising in healthy adults. Looney et al. ${ }^{23}$ reported decreased pain and improved motion performance in daily life, after application of IASTM in a patient having pain with plantar fasciitis. In studies that applied IASTM for neurological patients, Miller et al. ${ }^{24}$ reported increased range of ankle motion and improved motion performance in daily life in a child afflicted with cerebral palsy for more than 6 months. In subjects with spasticity, Lee et al. ${ }^{25}$ subjected the gastrocnemius to IASTM, to study the immediate effect on the reciprocal inhibition and innervation. They reported decreased muscle activation of the gastrocnemius, and increased muscle activation of the tibialis anterior. However, to date, there are few studies applying IASTM to stroke patients, and researching the direct comparison with other intervention techniques is also insufficient. Hence, we undertook to compare the effect on muscle tone, stiffness, and balance of the spastic region after exposure to IASTM and NDYT in subjects having hemiplegia due to stroke. We hypothesized that mechanical properties with over tension will decrease and balance will increase after intervention by both methods, and there will be a difference in outcome in comparison of the two methods.

\section{METHODS}

\section{Subjects}

Totally, 26 stroke patients hospitalized at the G hospital located in Daegu Metropolitan City. All subjects were fully informed about the study objec- tives and methods prior to the experiment and voluntary consent was received from each participant. Gender, age, weight, height, onset date, and spasticity of all subjects were assessed before the experiment, and subjects were randomly assigned to two groups. Inclusions for selecting a research subject were as follows: onset period of 6 or less months after being diagnosed as hemiplegia due to stroke, having scored 24 or more points of the Korean Mini Mental State Examination (K-MMSE), understanding and performing the details directed by the researcher. a patient who can stand on his own self for more than five minutes, spasticity level of 1 to 3 points as determined by the modified Ashworth scale (maximum 4 points). Patients who were treated injection for spasticity whithin the last 1 month, a patient with bruises or open wounds to the lower extremities, were excluded from the study. No significant differences in homogeneity and normality tests were found between the groups ( $p>0.05)$ (Table 1).

\section{Procedure}

The experiment was conducted for 6 weeks. We assessed mechanical properties of paretic lower limbs, static balance ability. The 26 subjects selected were divided into two groups: instrument assisted soft tissue mobilization (IASTM) group and neural dynamic technic (NDYT) group according to the intervention method. All subjects underwent general physical therapy 5 times a week for 30 minutes per section. Additionally, the IASTM group treated 5 times a week for 15 minutes per section. The NDYT group underwent the intervention 5 times a week for 15 minutes per section.

\section{Experimental methods}

\section{1) Neural dynamic technique}

This study applied the neural dynamic tensioner technique of extending Table 1. General characteristics of the subjects

\begin{tabular}{lcccc}
\hline Variables & IASTM $(\mathrm{n}=13)$ & NDYT $(\mathrm{n}=13)$ & $\mathrm{t}$ & $\mathrm{p}$ \\
\hline Gender (M/F) & & & & \\
$\mathrm{M}$ & $7(54 \%)$ & $8(61 \%)$ & & \\
$\mathrm{F}$ & $6(46 \%)$ & $5(39 \%)$ & & \\
Age (yr) & $66.0 \pm 8.4^{+}$ & $63.5 \pm 8.5$ & 0.74 & 0.465 \\
Weight (kg) & $62.8 \pm 10.1$ & $69.3 \pm 9.4$ & -1.70 & 0.101 \\
Height (cm) & $163.9 \pm 9.1$ & $168.9 \pm 9.1$ & -1.40 & 0.174 \\
MAS (score) & $1.2 \pm 0.4$ & $1.1 \pm 0.3$ & 1.06 & 0.296 \\
MMSE-K (score) & $24.9 \pm 1.0$ & $25.8 \pm 2.3$ & -1.31 & 0.200 \\
Stroke onset (m) & $2.5 \pm 1.6$ & $2.9 \pm 1.4$ & -0.65 & 0.520 \\
\hline
\end{tabular}

${ }^{+}$mean \pm standard deviation (SD).

MAS: Modified Ashworth Scale, MMSE-K: Mini Mental State Examination-Korean version, IASTM: Instrumental Assisted Soft tissue Mobilization, NDYT: Neural Dynamic Technique. 


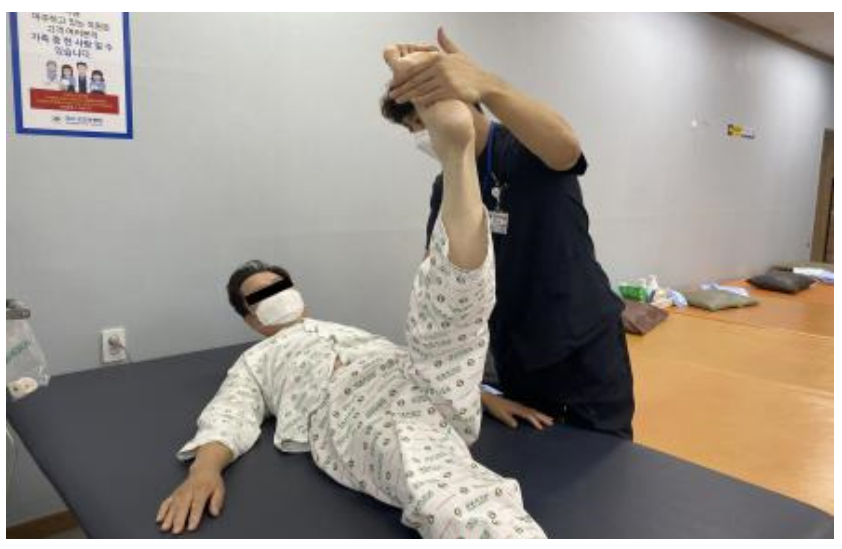

Figure 1. Neurodynamic Technique.

the total nerve length for tension application. ${ }^{26}$ Sciatic nerve dynamic technique, repetitive cervical flexion, followed by hip joint adduction and internal rotation in the Straight Leg Raise (SLR) position with ankle dorsiflexion, was performed in the supine position. In case of femoral nerve dynamic technique, the therapist maintained hip extension, knee flexion, and ankle plantar flexion on the paralytic side with cervical vertebrae extension, and hip and knee joints of flexion on nonparalytic side, with patient lying on his side. Intervention was done for a total of 15 minutes each cycle being: sciatic nerve ( $7 \mathrm{~min})$, rest (1 $\mathrm{min})$, femoral nerve $(7 \mathrm{~min})$ (Figure 1).

\section{2) Instrument assisted soft tissue mobilization}

The method of Laudner et al. ${ }^{27}$ was partially modified and applied to Instrument Assisted Soft Tissue Mobilization, using the Bodywork detector (Bodywork technique, Pangyo, South Korea). For application to the semitendinosus, IASTM was applied from the gluteal line to the popliteal region, with subject lying prone position on the mat having knee bent at $60^{\circ}$ and the paralytic side ankle resting on the chest of the therapist to facilitate comfortance. For application to the gastrocnemius medial region, IASTM was applied from the popliteal region to the calcaneus of the Achilles tendon by changing the knee posture from position to bending at $45^{\circ}$. For application to the tibialis anterior, IASTM was applied from upper part of the tibia and interosseous membrane to the part contacting lateral malleolus, after bending the knee at $45^{\circ}$ in the supine position. Stroking was applied to the bone interosseous membrane using rear end of the tool. Stroking was applied from the cranial direction to the causal direction, with the tool at $45^{\circ}$ incline and during intervention applied massage cream, according to the technique application guidelines. In order to control the strength and quantity of mechanical stimulation constantly, the metro-

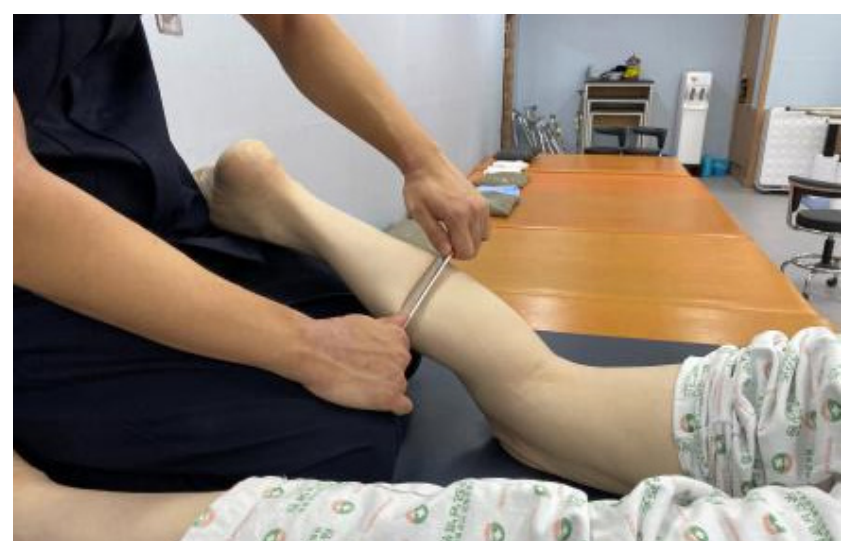

Figure 2. Instrumented Assisted Soft Tissue Mobilization.

nome was used and applied to each part $40 \mathrm{BPM}$. It was applied to each part for 5 minutes and applied for a total of 15 minutes (Figure 2).

\section{3) Measurement of paralytic side mechanical properties}

In order to maintain muscle tone and stiffness of the subject in the stable state, all measurements were done on the weekend when there was no treatment schedule. It was done in an independent place with no noise. The room temperature was maintained at $20-24^{\circ} \mathrm{C}$, and humidity at $50-$ $60 \%$. MyotonPRO (Myoton AS, Tallinn, Estonia) was used to measure the spasticity of the subject, and the tibialis anterior, the semitendinosus, and the gastrocnemius medial region were measured in the afflicted region, with the measurement taken in the central region of the belly of each muscle. ${ }^{28}$ The appropriate location was first indicated with a marker before commencing the measurement, and the average value was used after obtaining three measurements, according to the protocol suggested by the manufacturer. The reliability within the rater having the equipment applied to the biceps brachii of the stroke patient was determined to be ICC $0.86-0.96$, indicating high reliability of the equipment. ${ }^{29}$

\section{4) Balance ability measurement}

To measure the balancing stability of standstill subjects, the balance ability measurement software (Balancia software, Mintosys, Korea) was used on the basis of the Wii Balance Board, which was connected to the computer through Bluetooth. Measurements were achieved by collecting the pressure center information in real time through the 4 road cells. The collected pressure center data was analyzed through the Balancia software. The variables used in the research were the sway speed average, sway distance average, and $95 \%$ sway area average.

The measurements were performed in a comfortable standing position, 
after taking off shoes and standing on the pressure pad. The average value of three repetitive measurements was used, each measurement done for one minute. In order to prevent the subject from falling during measurement, the therapist provided close assistance. The pre-practice was conducted and measured to exclude learing effects. Reliability between the raters for the measurement of static balance ability of the Balancia software for stroke patients is $0.79-0.96$, with the validity of $0.85-0.96$ indicating high reliability and validity. ${ }^{30}$

\section{Statistical analysis}

Statistical analysis of the data collected was done using the SPSS for Windows ver. 25.0. (IBM Co. Armonk, NY, USA). The average and the standard deviation of the general characteristics of the subjects were found with the normality verification by applying Shapiro-Wilks. We used the paired t-test to respectively verify the difference between pre-and post-test mean values within the group. Independent t test was performed to compare the differences in variation between the groups, the statistical significance level $\alpha$ was set to 0.05 .

\section{RESULTS}

\section{General characteristics of subjects}

All subjects answered the questionnaires to determine general characteristics of gender, height, weight, and outbreak period. Finally, 26 subjects participated in the research. The general characteristics of the two groups are presented in Table 1.

\section{Difference in muscle tone and stiffness between groups}

Table 2 shows difference in muscle tone and stiffness between groups. In tibialis anterior, there was no significant difference between groups ( $p>0.05$ ), gastrocnemius medial region muscle tone was significant difference between groups. But, stiffness was no significant difference between groups. Semitendinosus shows significant difference between groups in both muscle tone and stiffness $(\mathrm{p}<0.05)$.

\section{Difference in static balance ability between groups}

Table 3 shows difference in static balance ability between groups. In static balance ability, there was no significant difference between groups in any items $(\mathrm{p}>0.05)$.

\section{DISCUSSION}

Our results indicate that mechanical properties of gastrocnemius medial region and semitendinosus showed significant difference in the IASTM group, as compared to the NDYT group $(\mathrm{p}<0.05)$. But, in tibialis anterior, there was no significant difference between groups ( $p>0.05$ ). Also, static balance ability showed no significant difference between two groups $(\mathrm{p}>0.05)$.

Table 2. Comparison of muscle tone and stiffness according to each group

\begin{tabular}{|c|c|c|c|c|c|c|c|}
\hline & & \multicolumn{2}{|c|}{ IASTM group $(n=13)$} & \multicolumn{2}{|c|}{ NDYT group $(n=13)$} & \multirow{2}{*}{$\mathrm{t}$} & \multirow{2}{*}{$p$} \\
\hline & & pre & post & pre & post & & \\
\hline \multirow[t]{2}{*}{ TA } & Tone $(\mathrm{Hz})$ & $19.63 \pm 3.54^{+}$ & $18.24 \pm 3.72$ & $19.61 \pm 2.06$ & $18.76 \pm 2.96$ & 0.054 & 0.585 \\
\hline & Stiffness (N) & $356.23 \pm 64.01$ & $338.53 \pm 59.62$ & $310.61 \pm 50.35$ & $309.61 \pm 55.59$ & 1.563 & 0.131 \\
\hline \multirow[t]{2}{*}{ GM } & Tone $(\mathrm{Hz})$ & $14.02 \pm 2.76$ & $14.22 \pm 1.86$ & $16.82 \pm 3.38$ & $15.12 \pm 2.43$ & -2.266 & $0.033^{*}$ \\
\hline & Stiffness (N) & $272.30 \pm 38.91$ & $270.53 \pm 28.81$ & $281.92 \pm 44.64$ & $267.23 \pm 32.79$ & -1.560 & 0.132 \\
\hline \multirow[t]{2}{*}{ ST } & Tone $(\mathrm{Hz})$ & $15.66 \pm 2.57$ & $13.93 \pm 1.21$ & $15.72 \pm 2.16$ & $15.90 \pm 2.50$ & 2.856 & $0.009^{*}$ \\
\hline & Stiffness (N) & $295.07 \pm 45.38$ & $263.69 \pm 29.67$ & $272.38 \pm 20.88$ & $277.53 \pm 31.89$ & 3.992 & $0.001^{*}$ \\
\hline
\end{tabular}

${ }^{+}$mean \pm standard deviation(SD).

IASTM: Instrumental Assisted Soft Tissue Mobilization, NDYT: Neural dynamic Technique, TA: tibialis anterior, GM: gastrocnemius medial region, ST: semitendinosus. ${ }^{*} \mathrm{p}<0.05$.

Table 3. Comparison of static balance ability according to each group

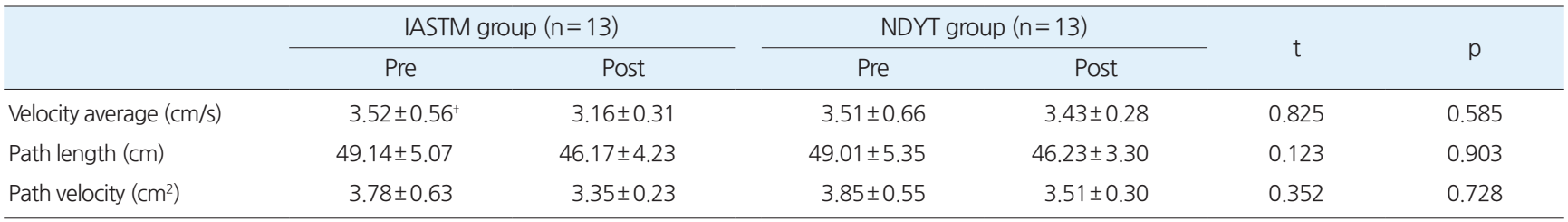

${ }^{+}$mean \pm standard deviation (SD).

IASTM: Instrumental Assisted Soft tissue Mobilization, NDYT: Neural Dynamic Technique. 
In this study shows significant difference between IASTM group with NDYT group in gastrocnemius medial region and semitendinosus. Markovic $^{31}$ explained that joint motion range and muscle tone were decreased IASTM group when compared to the group receiving static stretching, in juvenile soccer players. They reasoned that increasing temperature of the corresponding local region during application of stroking results in increased sliding of the fascia layer, and decreased collagen resistance. Our study determined that the IASTM group generated decreased muscle tone in comparison with the NDYT group, thereby supporting findings of the preceding research. Furthermore, according to Schleip ${ }^{32}$, muscle tone is lowered since the IASTM activates the mechanoreceptor of the inner layer of fascia and converts it into proprioceptive stimulation to affect the central nervous system. According to Simatou et al. ${ }^{33}$ IASTM uses the narrow surface area so that deeper penetration into the target is performed, with stimulation strength of the mechanoreceptor being different from that of another intervention method, which is similar to findings in our study.

In our study, there was no significant difference in mechanical properties of tibialis anterior. Lee et al. ${ }^{34}$ demonstrated that foot stiffness like claw foot in stroke patients, decreases function and balance ability of the lower extremity muscles. Parts of this study results, tibialis anterior muscular insertion site is located in medial cuneiform born and 1st metatarsal, plantar fasciae is located nearby. So, they reported there was strong links between higher tensions of plantar fasciae with increases tension of tibialis anterior. But, our study was not performed IASTM on the foot region. Whereas, in NDYT group, SLR (straight leg raise) with dorsiflexion was performed manually from the therapist, this position facilitated length of the plantar fascia. ${ }^{35}$ For this reason, there was no significant difference between groups in mechanical properties of tibialis anterior.

In our study, there was no significant difference in balance ability between groups. Balance is defined as the ability to maintain the body in equilibrium, and maintain the center of mass within an unstable surface. Balance requires proper interaction of joint mobility, sensory system, central nervous system, and musculoskeletal system. ${ }^{36,37}$ In this context, to improve balance ability, the mechanical properties of the muscles are important, but it is also very important to train other element of balance together, like a proprioceptive sensation and muscle strength. However, in this study was conducted simply by focusing on the mechanical characteristics of the muscles, other factors that might affect the balance ability were excluded, and it seems that there was no difference in balance ability between the two groups. Therefore, future research will need to investigate the difference between the two methods by performing other interven- tions related to balance ability.

In our study have some limitations. First, the number of subjects is not large (13 subjects per group); hence, it is difficult to generalize the results to all stroke patients. Second, as there is no agreement on the application period and strength of IASTM, it is difficult to prepare a standard for the comparison with another intervention technique. Therefore, further research on comparing the effect with another intervention technique should be done by including more subjects with the limitations supplemented, and by preparing the standards of proper application period and strength of the IASTM. Third, in mechanical properties of gastrocnemius medial region, there was significant difference in muscle tone but no significant difference in stiffness between groups. Our study could not explained this outcomes

The current study endeavored to compare effects of two therapeutic methods (IASTM and NDYT) on the muscle tone, stiffness, and static balance ability of lower extremity in acute stroke patients. Spasticity develops as a result of CNS injury, leading cause of secondary changes within the muscles and connective tissues also contribute to muscle tension and stiffness, our results suggest that IASTM is appropriate intervention method with no adverse effect used in stroke patients. And also, in the study has no significant difference in balance between groups, but if think that appropriate combination of both therapeutic methods is considered help to prevent a change in the mechanical properties due to spasticity.

\section{REFERENCES}

1. Adamson J, Beswick A, Ebrahim S. Is stroke the most common cause of disability? J Stroke Cerebrovasc Dis. 2004;13(4):171-7.

2. Fatone S, Hansen AH. Effect of ankle-foot orthosis on roll-over shape in adults with hemiplegia. J Rehabil Res Dev. 2007;44(1):11-20.

3. Kollen BJ, Lennon S, Lyons B et al. The effectiveness of the Bobath concept in stroke rehabilitation: what is the evidence?. Stroke. 2009;40 (4):e89-97.

4. Lance JW. The control of muscle tone, reflexes, and movement: Robert Wartenberg Lecture. Neurology. 1980;30(12):1303-13.

5. Young RR. Spasticity: a review. Neurology. 1994;44:S12-20.

6. Dietz V, Sinkjaer T. Spastic movement disorder: impaired reflex function and altered muscle mechanics. Lancet Neurol. 2007;6(8):725-33.

7. Mayer NH, Esquenazi A. Muscle overactivity and movement dysfunction in the upper motoneuron syndrome. Phys Med Rehabil Clin N Am. 2003;14(4):855-83.

8. Duncan PW, Zorowitz R, Bates B et al. Management of Adult Stroke Rehabilitation Care: a clinical practice guideline. Stroke. 2005;36(9):e10043.

9. Dickstein R, Laufer Y, Katz M. TENS to the posterior aspect of the legs decreases postural sway during stance. Neurosci Lett. 2006;393(1):51-5. 
10. Thibaut A, Chatelle C, Ziegler E et al. Spasticity after stroke: physiology, assessment and treatment. Brain inj. 2013;27(10):1093-105.

11. Doan QV, Brashear A, Gillard PJ et al. Relationship between disability and health-related quality of life and caregiver burden in patients with upper limb poststroke spasticity. PM\&R. 2012;4(1):4-10.

12. Alabdulwahab SS, Al-Gabbani M. Transcutaneous electrical nerve stimulation of hip adductors improves gait parameters of children with spastic diplegic cerebral palsy. NeuroRehabilitation. 2010;26(2):115-22.

13. Noma T, Matsumoto S, Shimodozono M et al. Anti-spastic effects of the direct application of vibratory stimuli to the spastic muscles of hemiplegic limbs in post-stroke patients: a proof-of-principle study. J Rehabil Med. 2012;44(4):325-30.

14. Alcantara CC, Blanco J, De Oliveira LM et al. Cryotherapy reduces muscle hypertonia, but does not affect lower limb strength or gait kinematics post-stroke: a randomized controlled crossover study. Top Stroke Rehabil. 2019;26(4):267-80.

15. Lee GP, Ng GY. Effects of stretching and heat treatment on hamstring extensibility in children with severe mental retardation and hypertonia. Clin Rehabil. 2008;22(9):771-9.

16. Coppieters MW, Butler DS. Do 'sliders' slide and 'tensioners' tension? An analysis of neurodynamic techniques and considerations regarding their application. Man Ther. 2008;13(3):213-21.

17. Shacklock M. Improving application of neurodynamic (neural tension) testing and treatments: a message to researchers and clinicians. Man Ther. 2005;10(3):175-9.

18. Braun M, Schwickert M, Nielsen A et al. Effectiveness of traditional Chinese "gua sha" therapy in patients with chronic neck pain: a randomized controlled trial. Pain Med. 2011;12(3):362-9.

19. Loghmani MT, Warden SJ. Instrument-assisted cross-fiber massage accelerates knee ligament healing. J Orthop Sports Phys Ther. 2009;39 (7):506-14.

20. Villafañe JH, Silva GB, Chiarotto A et al. Botulinum toxin type A combined with neurodynamic mobilization for upper limb spasticity after stroke: a case report. J Chiropr Med. 2012;11(3):186-91.

21. Castilho J, Ferreira LAB, Pereira WM et al. Analysis of electromyographic activity in spastic biceps brachii muscle following neural mobilization. J Bodyw Mov Ther. 2012;16(3):364-8.

22. Cheatham SW, Kreiswirth E, Baker R. Does a light pressure instrument assisted soft tissue mobilization technique modulate tactile discrimination and perceived pain in healthy individuals with DOMS? J Can Chiropr Assoc. 2019;63(1):18-25.

23. Looney B, Srokose T, Cleland JA et al. Graston instrument soft tissue mobilization and home stretching for the management of plantar heel pain: a case series. J Manipulative and Physiol Ther. 2011;34(2):138-42.

24. Miller MM, Ray JM, Van Zant RS. The Effects of Astym Therapy(R) on a Child With Spastic Diplegic Cerebral Palsy. Clin Med Insights Case Rep. 2017;10:1179547617746992.

25. Lee JJ, Lee JJ, Kim DH et al. Inhibitory effects of instrument-assisted neuromobilization on hyperactive gastrocnemius in a hemiparetic stroke patient. Biomed Mater Eng. 2014;24(6):2389-94.

26. Sharma S, Balthillaya G, Rao R et al. Short term effectiveness of neural sliders and neural tensioners as an adjunct to static stretching of hamstrings on knee extension angle in healthy individuals: A randomized controlled trial. Phys Ther Sport. 2016;17:30-7.

27. Laudner K, Compton BD, McLoda TA et al. Acute effects of instrument assisted soft tissue mobilization for improving posterior shoulder range of motion in collegiate baseball players. Int J Sports Phys Ther. 2014; 9(1):1-7.

28. Dellana LE, Chen F, Gandelman JS et al. Reproducibility of the durometer and myoton devices for skin stiffness measurement in healthy subjects. Skin Res Technol. 2019;25(3):289-93.

29. Chuang LL, Wu CY, Lin KC et al. Quantitative mechanical properties of the relaxed biceps and triceps brachii muscles in patients with subacute stroke: a reliability study of the myoton-3 myometer. Stroke Res and Treat. 2012;2012:617694.

30. Park DS, Lee DY, Choi SJ et al. Reliability and validity of the balancia using wii balance board for assessment of balance with stroke patients. J Kor Acad Ind Coop Soc. 2013;14(6):2767-72.

31. Markovic G. Acute effects of instrument assisted soft tissue mobilization vs. foam rolling on knee and hip range of motion in soccer players. J Bodyw Mov Ther. 2015;19(4):690-6.

32. Schleip R. Fascial plasticity-a new neurobiological explanation Part 2. J Bodyw Mov Ther. 2003;7(2):104-16.

33. Simatou M, Papandreou M, Billis E et al. Effects of the Ergon( $\left(^{\circ}\right)$ instrument-assisted soft tissue mobilization technique (IASTM), foam rolling, and static stretching application to different parts of the myofascial lateral line on hip joint flexibility. J Phys Ther Sci. 2020;32(4):288-91.

34. Lee KB, Kim BR, Lee KS. Effects of toe spreader on plantar pressure and gait in chronic stroke patients. Technol Health Care. 2018;26(6):957-62.

35. Lim AT, How CH, Tan B. Management of plantar fasciitis in the outpatient setting. Singapore Med J. 2016;57(4):168-70.

36. Woollacott M, Shumway-Cook A. Attention and the control of posture and gait: a review of an emerging area of research. Gait Posture. 2002;16 (1):1-14.

37. Corriveau H, Hébert R, Raîche M et al. Evaluation of postural stability in the elderly with stroke. Arch Phys Med Rehabil. 2004;85(7):1095-101. 